\title{
A ABORDAGEM DOS DIREITOS HUMANOS NA ATUAÇÃO DA CORTE PENAL INTERNACIONAL
}

\author{
THE HUMAN RIGHTS APPROACH IN THE WORK OF THE \\ INTERNATIONAL CRIMINAL COURT
}

\author{
Recebimento: 16 jun. 2020 \\ Aceitação: 22 mar. 2021 \\ Karla Pinhel Ribeiro \\ Doutora em Filosofia \\ Afiliação institucional: Centro Universitário Curitiba - UNICURITIBA - (Curitiba, PR, Brasil) \\ Lattes iD: http://lattes.cnpq.br/7479262758658154 \\ Email: karlapinhelribeiro@gmail.com \\ Nicole França Bergamini \\ Bacharelanda em Direito \\ Afiliação institucional: Centro Universitário Curitiba - UNICURITIBA - (Curitiba, PR, Brasil) \\ Lattes iD: http://lattes.cnpq.br/3539154177949193 \\ Email: nicolefrancabergamini@gmail.com
}

Como citar este artigo / How to cite this article (informe a data atual de acesso / inform the current date of access):

RIBEIRO, Karla Pinhel; BERGAMINI, Nicole França. A abordagem dos direitos humanos na atuação da Corte Penal Internacional. Revista da Faculdade de Direito UFPR, Curitiba, v. 66, n. 1, p. 197-219, jan./abr. 2021. ISSN 22367284. Disponível em: https://revistas.ufpr.br/direito/article/view/74532. Acesso em: 30 abr. 2021. DOI: http://dx.doi.org/10.5380/rfdufpr.v66i1.74532.

\section{RESUMO}

Esta pesquisa pretende investigar se uma releitura dos princípios de direito internacional público presentes na delimitação da jurisdição da Corte Penal Internacional pode viabilizar uma atuação mais eficaz da Corte, baseada na soberania popular, no human rights approach e no diálogo entre a jurisdição penal internacional e a nacional. Nesse panorama, estabeleceu-se o seguinte problema de pesquisa: Como uma abordagem baseada no human rights approach pode tornar a atuação da Corte Penal Internacional mais efetiva para populações que sofrem pela perpetração dos crimes definidos no Estatuto de Roma? Realizou-se o exame da conexão entre as normas de jurisdição decorrentes dos princípios baseados no state approach e as adversidades encontradas pela comunidade internacional para uma atuação eficaz da Corte Penal Internacional, mediante pesquisa bibliográfica e análise jurisprudencial, seguidas pela verificação da viabilidade em se usar o human rights approach para solucionar problemas de eficácia enfrentados pela Corte. O material utilizado foi composto por livros, artigos científicos e outras publicações em periódicos, bem como pela coleta de informações veiculadas pelos Estados-partes do Estatuto de Roma. Assim, verificou-se a emergência do paradigma pautado no human rights approach no direito internacional público, em especial no ordenamento jurídico da Corte Penal Internacional, cuja eclosão apresenta uma oportunidade para uma atuação mais eficaz da Corte, voltada para o desenvolvimento comunitário. 


\title{
PALAVRAS-CHAVE
}

Corte Penal Internacional. Jurisdição. Human rights approach. Princípios de direito internacional público.

\begin{abstract}
This research intends to investigate whether a reinterpretation of the principles of public international law present in the delimitation of the jurisdiction of the International Criminal Court can enable a more effective performance of the Court, based on popular sovereignty, the human rights approach and the dialogue between international and national criminal jurisdiction. In this context, the following research problem was established: How can a concept based on the human rights approach make the work of the International Criminal Court more effective for populations that suffer from the perpetration of the crimes defined in the Rome Statute? An examination of the connection between the rules of jurisdiction arising from the principles based on the state approach and the adversities encountered by the international community for an effective performance of the International Criminal Court was carried out, through bibliographic research and jurisprudential analysis, followed by the verification of the feasibility in using the human rights approach to solving problems of effectiveness faced by the Court. Books, scientific articles and other publications in periodicals, as well as information conveyed by the States parties to the Rome Statute were used in this research. It was possible to verify the emergence of the paradigm based on the human rights approach in public international law, especially in the legal system of the International Criminal Court, and that this represents an opportunity for more effective action by the Court, focused on community development.
\end{abstract}

\section{KEYWORDS}

International Criminal Court. Jurisdiction. Human rights approach. Principles of public international law.

\section{INTRODUÇÃO}

O Estatuto de Roma, tratado que criou a Corte Penal Internacional, ratificado pelo Brasil em 2002 e internalizado no ordenamento jurídico nacional por meio do Decreto $n^{\circ}$ 4.388/2002, postula em seu preâmbulo os objetivos da Corte; entre eles, colocar um fim à impunidade dos perpetradores de crimes de maior gravidade, que afetam a comunidade internacional no seu conjunto, contribuir para a prevenção desses crimes, reforçar a cooperação internacional e garantir o respeito duradouro pela efetivação da justiça internacional (INTERNATIONAL CRIMINAL COURT, 1998).

Ao lado desses objetivos, o próprio preâmbulo pontua uma série de princípios que guiam e delimitam a atuação da Corte Penal Internacional. No entanto, alguns desses princípios, com o desenvolvimento do direito penal internacional, tornaram-se um empecilho para atuação efetiva da Corte. Cuida-se aqui dos princípios da soberania, complementaridade e pacta sunt servanda.

Nesse sentido, é forçoso notar que, data venia sua imperativa presença no direito internacional atual, a Corte Penal Internacional, em prol de garantir o respeito a esses princípios, quedou-se omissa ante graves crimes internacionais, assim abrindo espaço para críticas da 
comunidade internacional no que se refere à sua atuação ante seus objetivos primordiais, em especial a proteção dos direitos humanos.

Em que pese a jurisdição da Corte Penal Internacional seja validada por intermédio da soberania estatal dos Estados signatários ao Estatuto de Roma, essa relação de interdependência também tem limitado a ação da corte, de modo a colocar em risco sua existência.

Diante do referido panorama, estabeleceu-se o seguinte problema de pesquisa: Como uma abordagem baseada no human rights approach pode tornar a atuação da Corte Penal Internacional mais efetiva para populações que sofrem pela perpetração dos crimes definidos no Estatuto de Roma?

Nesse sentido, propôs-se como hipótese inicial que uma releitura dos princípios de direito internacional público, presentes na jurisdição da Corte Penal Internacional, baseada na soberania popular, no human rights approach e no diálogo entre a jurisdição penal internacional e nacional pode viabilizar uma atuação mais eficaz da Corte.

Para a verificação da hipótese descrita, estabeleceram-se três objetivos específicos. O primeiro consistiu em identificar como a limitação de determinados princípios de direito internacional público se torna um empecilho para a atuação eficaz da Corte Penal Internacional.

Em seguida, objetivou-se verificar a necessidade de tornar a ação da Corte Penal Internacional mais dinâmica para garantir que os objetivos estabelecidos no preâmbulo do Estatuto de Roma sejam alcançados pela comunidade internacional como um todo. E, por fim, buscou-se analisar o human rights approach como uma base epistemológica válida para ressignificar os princípios basilares da jurisdição da Corte Penal Internacional e capaz de proporcionar maior eficácia à sua atuação.

Para tanto, o presente trabalho adotou a metodologia de pesquisa a seguir descrita. Inicialmente, identificou-se, por meio de pesquisa bibliográfica, como a comunidade científica percebe a aplicação dos referidos princípios, decorrentes do paradigma pautado no state-based approach, no direito internacional público de maneira geral, em especial depois da consolidação dos direitos humanos.

Após, verificou-se como a aplicação desses princípios ocorre no âmbito da Corte Penal Internacional e como isso afeta sua atuação. Para isso, foi feita a análise do Estatuto de Roma e da jurisprudência da Corte, no que se refere à jurisdição e admissibilidade de casos, bem como a coleta de informações acerca da recepção, pelos Estados-partes, do tratado das decisões analisadas.

A partir dos resultados obtidos, passou-se a estabelecer a relação entre as críticas feitas à eficácia da Corte Penal Internacional e a aplicação dos princípios pautados no state-based approach. 
Ademais, o trabalho utilizou pesquisa bibliográfica para conceituar o human rights approach. Em seguida, com a análise do Estatuto de Roma e com a coleta de dados sobre a atuação da Corte Penal Internacional fora do escopo da persecução penal, verificou-se a viabilidade jurídica e fática de se utilizar uma abordagem voltada para os direitos humanos para solucionar os problemas de eficácia enfrentados pela Corte, em especial devido às normas de jurisdição e admissibilidade de casos.

Ao final da pesquisa, a hipótese inicial foi parcialmente verificada, com a devida ressalva à função cumprida pelos princípios pautados no state approach na preservação dos direitos dos réus perante a Corte Penal Internacional.

Desse modo, o presente trabalho se inicia contextualizando a crise do paradigma baseado no state approach percebida no direito internacional público. Então, passa a identificar os sintomas dessa crise de paradigma na atuação da Corte Penal Internacional, para depois estabelecer a relação entre a natureza das normas sob as quais a Corte Penal Internacional está pautada e as dificuldades de atuação por ela enfrentadas.

Logo após, trata-se da emergência da aplicação do paradigma baseado no human rights approach no âmbito do direito internacional público. Nesse sentido, cuida-se de conceituar a abordagem baseada nos direitos humanos, para então dirigir-se à necessidade dessa abordagem no escopo de atuação da Corte Penal Internacional.

Isso posto, o trabalho faz a devida ressalva acerca da relação entre a releitura dos princípios pautados no state approach e os direitos dos réus perante a Corte Penal Internacional e discorre a respeito da possibilidade de atuação da Corte Penal Internacional fora do escopo da persecução penal, concluindo-se com as considerações finais sobre a pesquisa realizada.

A urgência e relevância do tema demonstra a necessidade do estudo para a continuidade dessa marcante instituição no direito internacional. Uma releitura de seus princípios e modo de atuação possibilita ao direito penal internacional ampliar seu escopo de trabalho, para desempenhar um papel não apenas na justiça repressiva, mas também no desenvolvimento comunitário de populações atingidas por crimes previstos pelo Estatuto de Roma.

Nesse contexto, uma interpretação baseada nos direitos humanos, com enfoque nos ideais de soberania popular, dignidade da pessoa humana e garantindo preponderância ao human rights approach pode basear uma atuação mais ativa da Corte Penal Internacional em relação aos sistemas criminais nacionais, inclusive possibilitando o ius commune internacional. 


\section{A CRISE DO PARADIGMA BASEADO NO STATE APPROACH}

Inicialmente, cumpre delimitar que a presente pesquisa adota um especial enfoque no sistema de jurisdição e admissibilidade da Corte Penal Internacional, que guarda relação intrínseca com os princípios da soberania, complementaridade e pacta sunt servanda. Esses princípios, voltados para a proteção do Estado, pautam-se em um state-based approach.

Uma epistemologia baseada no state approach ou state-centered perspective, daqui em diante referida como abordagem voltada para o Estado, trata-se de uma ótica que toma por base de seus conceitos estruturais e fundantes a soberania do Estado em suas relações exteriores, bem como na perspectiva de proteção da autonomia e independência do Estado (PIOVESAN, 2013, p. 390). Trata-se de um prisma cuja matriz está ligada à “lente ex parte principe” (BOBBIO, 2004, p. 50).

Todavia, não se pode esquecer que a primazia por esses princípios, pautados na abordagem voltada para o Estado, no âmbito geral do direito internacional público, tem se mostrado, em certa medida, incompatível com a intenção da comunidade internacional de garantir que os direitos humanos de todos os cidadãos sejam respeitados pelos Estados.

Nesse sentido, o conflito entre as referidas normas gira em torno do limite de capacidade da comunidade internacional em assegurar a proteção dos direitos humanos, quando confrontada com os princípios pautados em uma abordagem voltada para o Estado. Notadamente no que diz respeito às implicações dos dogmas de independência e não intervenção nos assuntos internos de um Estado, se ausente o consentimento estatal e o compromisso com tratados de direitos humanos (BARREIROS, 2008, p. 77).

Na mesma perspectiva, o desenvolvimento das questões geopolíticas atualmente enfrentadas pela comunidade internacional é uma das causas do conflito entre as referidas normas e, por conseguinte, da crise do paradigma baseado na abordagem voltada para o Estado (DOMINGOS, 2012, p. 1.572).

Ademais, não se pode esquecer que o conflito entre a proteção aos direitos humanos e a preservação da soberania estatal também surge como consequência da globalização, na medida em que as relações globais atuais demandam um nível de flexibilidade que é de difícil compatibilização com os dogmas protetivos tradicionais, compreendidos na abordagem voltada para o Estado, a exemplo do princípio da soberania (DOMINGOS, 2012, p. 1.557).

Cumpre ainda ressalvar que em seu desenvolvimento, os princípios baseados na abordagem voltada para o Estado deixaram de apresentar aplicação absoluta, sendo que a proteção aos direitos humanos foi grande responsável pela relativização de princípios como o da soberania estatal. Isso 
ocorre na medida em que, em nome da proteção aos direitos humanos, houve a codificação de normas que limitam as prerrogativas do Estado e de seus governantes (GÜMPLOVÁ, 2015, p. 11).

Assim, a comunidade internacional responsabilizou-se por fortalecer princípios e regras aplicáveis à relação entre os governantes e os cidadãos, visando à proteção a tais direitos fundamentais de todas e todos (COHEN, 2012, p. 2 apud GÜMPLOVÁ, 2015, p. 12).

Por conseguinte, houve o advento de instituições e órgãos internacionais que objetivam a proteção dos direitos, por intermédio de medidas efetivas que compelem os Estados a atuar conforme o padrão universal de justiça, resultando também, em determinada medida, em uma relativização dos princípios de proteção ao Estado (GÜMPLOVÁ, 2015, p. 11).

Nota-se, então, que as referidas relativizações em regimes que adotam a abordagem voltada para o Estado, decorrentes da consolidação dos direitos humanos, são consequência da própria natureza das pretensões de proteção a tais direitos.

Todavia, depreende-se ser imperativo ressalvar que as mencionadas exigências, feitas por entes internacionais que objetivam a proteção dos direitos humanos, são, de maneira geral, condicionadas ao crivo estatal. Isso porque os tratados internacionais apenas serão aplicáveis aos Estados que forem signatários, em observância ao princípio pacta sunt servanda, assim como devido à necessidade de se reconhecer a jurisdição de cortes internacionais, consoante o princípio da soberania.

Nesse sentido, o embate entre a jurisdição local e global, do qual decorre a necessidade de se conceder soberania mediante a assinatura de tratados e ceder poderes jurídicos para a atuação de entes internacionais evidencia que os "[t]ratados deixaram de ser um meio efetivo de lidar com problemas globais e a legalidade internacional é com frequência danificada pelo zelo político de um grupo de nações que detêm maior poder” (DOMINGOS, 2012, p. 1.553).

Por conseguinte, não se pode evitar reconhecer que o paradigma pautado em uma abordagem baseada no Estado está em crise. Notadamente no que se refere ao princípio da soberania, o qual “não mais proporciona um enquadramento adequado e esclarecedor para um pluriverso global de regimes legais e políticos e subsistemas da sociedade mundial, perante os quais a soberania estatal tem se tornado obsoleta”1 (GÜMPLOVÁ, 2015, p. 10, tradução nossa).

No mesmo seguimento, o contexto geopolítico atual e a mudança de paradigma nas relações internacionais demandam um novo ordenamento jurídico que não esteja limitado pela abordagem baseada no Estado (DOMINGOS, 2012, p. 1.580).

1 No original: “[...] no longer provides an adequate explanatory framework for a global pluriverse of legal and political regimes and subsystems of the world society in which sovereign states are becoming obsolete.” 
Assim, verifica-se que a consolidação dos direitos humanos, por intermédio dos órgãos internacionais que visam à sua proteção, foi responsável por relativizar os princípios pautados na abordagem voltada para o Estado. No entanto, denota-se que a aludida relativização se tornou insuficiente para a resolução de conflitos entre normas que protegem os direitos humanos e normas que protegem a soberania estatal, evidenciando-se a crise que o paradigma baseado na abordagem voltada para o Estado enfrenta perante a comunidade internacional.

\subsection{OS SINTOMAS DA CRISE DO PARADIGMA NA ATUAÇÃO DA CORTE PENAL INTERNACIONAL}

No mesmo sentido, é possível observar nos reflexos do crescente corpo de julgados da Corte Penal Internacional que a instituição também enfrenta impasses decorrentes do conflito entre as normas que visam à proteção da soberania estatal, pautadas na abordagem voltada para o Estado, e as normas de proteção aos direitos humanos, notadamente no que se refere à possibilidade de se promover investigações e persecuções criminais perante a Corte.

Nos últimos anos, a Corte Penal Internacional foi alvo de duras críticas em decorrência de seu posicionamento acerca da inadmissibilidade de determinadas situações de preocupação internacional. Refere-se aqui às considerações feitas quando a África do Sul anunciou a retirada do Estado do Estatuto de Roma (DYANI-MHANGO, 2018, p. 268)², reforçadas com o anúncio de retirada do tratado pela Gâmbia ${ }^{3}$ e Burundi, bem como por manifestações da União Africana (SSENYONJO, 2017, p. 64).

Ao anunciar que deixaria o Estatuto, a África do Sul criticou a Corte por ter julgado até então em grande maioria casos de países africanos, enquanto diversas situações de possíveis crimes internacionais cometidos em ou por países do hemisfério norte como os Estados Unidos e a Rússia não eram alcançadas pelas investigações da $\operatorname{Corte}^{4}$ (SSENYONJO, 2017, p. 76).

2 Ressalva-se que posteriormente a comunicação de retirada da África do Sul do Estatuto de Roma foi considerada inconstitucional no âmbito nacional com o julgamento Democratic Alliance v. Minister of International Relations and Cooperation, 2017, tendo em vista que a decisão de retirada do Estatuto não foi submetida ao crivo do parlamento nacional.

3 Ressalva-se que posteriormente, em dezembro de 2016, o Presidente Yahya Jammeh, cujo governo foi responsável pela notificação de retirada do Estado do Estatuto de Roma, perdeu as eleições na Gâmbia, sendo que o então recém eleito, presidente Adama Barrow, retirou a notificação de retirada do Estatuto, de modo que atualmente a Gâmbia continua um Estado-parte da Corte Penal Internacional.

4 Ocorre que, ao analisar o sistema jurídico da Corte percebe-se que essas situações estão além do escopo jurisdicional estabelecido pelo Estatuto de Roma justamente devido aos princípios da soberania, complementaridade e pacta sunt servanda que vinculam a atuação da Corte. 
Esse argumento foi reforçado pelo Estado da Gâmbia, quando seu Ministro da Informação, Sheriff Baba Bojang, referindo-se à notificação de saída da Gâmbia da Corte, declarou que a Corte Penal Internacional “é na verdade uma Corte Caucasiana Internacional para a persecução e humilhação de pessoas de cor, especialmente africanos”5 (GAMBIA..., 2016, tradução nossa).

Não obstante se atribua às motivações das decisões de retirada do Estatuto por Burundi e Gâmbia uma perspectiva de se evitar uma persecução criminal pela Corte Penal Internacional em face dos chefes de governo desses Estados (SSENYONJO, 2017, p. 68), destaca-se que não se deve subestimar a crítica feita por Estados signatários do Estatuto de Roma, tão pouco sua influência na credibilidade da Corte Penal Internacional, especialmente na medida em que o exercício da jurisdição da Corte está diretamente relacionado à legitimidade a ela conferida pelos Estados-partes.

Ademais, merece destaque nessa seara as dificuldades enfrentadas pela Corte Penal Internacional no caso Al Bashir. Depois de iniciada a investigação da situação em Darfur, a Câmara de Pré-Julgamento I deferiu o pedido da Procuradoria e emitiu dois mandados de prisão em face de Omar Al Bashir, em quatro de março de 2009 e em 12 de julho de 2010, pelos crimes de genocídio, crimes contra humanidade e crimes de guerra em tese por ele cometidos contra membros dos grupos Fur, Masalit e Zaghawa em Darfur entre 2003 e 14 de julho de 2008 (COUR PÉNALE INTERNATIONALE, 2009, 2010).

Não obstante, até a data do desenvolvimento da presente pesquisa, Al Bashir não havia sido julgado pelos crimes dos quais é acusado, tendo em vista que os mandados não foram executados e que o Estatuto de Roma (INTERNATIONAL CRIMINAL COURT, 1998) prevê expressamente, no artigo 63, a impossibilidade de se promover julgamentos na ausência do acusado. Ocorre que, para que a Corte Penal Internacional promova a persecução criminal de Al Bashir, a instituição depende de que o acusado se apresente voluntariamente à Corte, ou ainda que ele seja entregue à Corte por um Estado.

No entanto, os Estados da África do Sul, Chade, Quênia, Djibouti e Malawi, todos signatários do Estatuto de Roma, receberam Omar Al Bashir e quedaram-se inertes ao mandado de prisão, bem como ao pedido explícito da Corte Penal Internacional de assistência para a apreensão de Al Bashir (GREENAWALT, 2012, p. 393).

Nesse sentido, verifica-se que as manifestações feitas pela União Africana e pelos Estados da África do Sul, Gâmbia e Burundi e as dificuldades enfrentadas para dar seguimento ao procedimento aberto em face de Al Bashir explicitam como os princípios que encontram respaldo em

5 No original: “[...] is in fact an International Caucasian Court for the persecution and humiliation of people of colour, especially Africans.” 
uma abordagem voltada para o Estado estão intrinsecamente ligados às críticas feitas quanto à falta de eficácia da Corte Penal Internacional.

\subsection{A RELAÇÃO ENTRE A NATUREZA DAS NORMAS SOB AS QUAIS A CORTE PENAL INTERNACIONAL ESTÁ PAUTADA E AS DIFICULDADES DE ATUAÇÃO POR ELA ENFRENTADAS}

Verifica-se em análise aos recentes embates enfrentados pela Corte Penal Internacional para a efetivação das previsões de seu Estatuto, bem como para o desenvolvimento de sua atuação em conformidade com os objetivos encartados no preâmbulo do Estatuto de Roma, em especial o propósito de garantir o fim da impunidade aos crimes mais sérios de preocupação internacional, que há uma inegável ligação entre os já aludidos impasses e as normas compreendidas na estrutura jurídica da Corte, que encontram embasamento em uma abordagem voltada para a proteção do Estado.

No que se refere ao embate entre os posicionamentos da Corte Penal Internacional e da União Africana e de seus membros, afirma-se que “o resultado dessas decisões também destaca os limites do poder coercitivo da Corte Penal Internacional” (GREENWALT, 2012, p. 395). No mesmo sentido, percebe-se que

[a] Corte Penal Internacional está em posição tal que pode tanto tornar-se uma corte internacional obsoleta, quanto tornar-se uma corte internacional viável, uma vez que os recentes eventos no Quênia e no Chade ${ }^{[6]}$ expuseram as fissuras que existem no Estatuto de Roma $^{[7]}$ (BARNES, 2011, p. 1.619, tradução nossa).

A esse respeito, ante o escopo da presente pesquisa, entende-se necessário ressalvar que as fissuras expostas pelo recente embaraço decorrente do caso Al Bashir decorrem justamente do fato de que o Estatuto de Roma foi elaborado em um contexto de transição paradigmática (BARNES, 2011, p. 1.589).

Nesse contexto, em que pese a atuação da comunidade internacional volte-se primariamente à proteção dos direitos humanos, a viabilidade da contratação entre Estados e a criação de instituições internacionais ainda estão condicionadas à manutenção dos princípios pautados na abordagem voltada para o Estado.

6 Nesse ponto o autor se refere à inércia dos Estados do Quênia e Chade em relação aos mandados de prisão do então Presidente Omar Al Bashir emitidos pela Câmara de Pré-Julgamento I, da Corte Penal Internacional, em quatro de março de 2009 e em 12 de julho de 2010, bem como ante o pedido expresso de cooperação para a apreensão e entrega de Al Bashir à Corte.

7 No original: "The ICC is in a position that could make it either obsolete or a viable international court because the recent events in Kenya and Chad have exposed the cracks existing in the Rome Statute.” 
Ante essas e outras semelhantes adversidades, ao observar as dificuldades do exercício de um poder hierarquizado no plano do direito penal internacional, destaca-se que, ao contrário do que ocorre no plano nacional, em que há uma organização vertical com hierarquização política que centraliza em si o exercício do poder, na esfera internacional, os Estados não se organizam de tal maneira, especialmente na medida em que, via de regra, não cedem sua soberania em prol de organizações internacionais que ocupem posição hierarquicamente superior (DISSENHA, 2013, p. 155).

\begin{abstract}
De fato, o Direito Internacional se fundamenta em uma imperatividade diferente daquela existente no plano nacional, pois se pode entender que internacionalmente, o Direito se respeita como manifestação direta da vontade das partes envolvidas a partir de uma voluntary compliance capaz de justificar o gigantesco número de decisões, acordos, normas que compõem o Direito Internacional e que dão prova de sua existência. É nessa forma jurídica desenhada segundo uma construção originalmente horizontal que o Direito Internacional se desenvolve, a partir do rompimento com o modelo da Westphalia, segundo uma proposta predominantemente igualitária e que aceita qualquer forma de Estado/governo, mesmo aquelas não democráticas. (DISSENHA, 2013, p. 155).
\end{abstract}

Assim, os aludidos mecanismos, previstos na primeira parte do Estatuto de Roma, que regulam a maneira pela qual a Corte Penal Internacional exercerá sua jurisdição, decorrem justamente do caráter horizontal do direito internacional. Não obstante a Corte Penal Internacional seja exemplo de um foco de poder oriundo da convergência de interesses entre os Estados (DISSENHA, 2013, p. 155), o poder exercido pela Corte não é absoluto, conforme preconiza o princípio da complementaridade.

Esse princípio foi encartado explicitamente no Estatuto de Roma na forma do artigo 17 (INTERNATIONAL CRIMINAL COURT, 1998), bem como em seu preâmbulo, nos termos da redação adotada pelo Decreto ${ }^{\circ}$ 4.388/2002: “Sublinhando que o Tribunal Penal Internacional, criado pelo presente Estatuto, será complementar às jurisdições penais nacionais” (BRASIL, 2002).

Desse modo, denota-se que, em que pese as limitações impostas pelos princípios da complementaridade, soberania, pacta sunt servanda, assim como outros que encontram respaldo em uma abordagem voltada para o Estado, tenham por finalidade simultaneamente garantir proteção aos Estados-partes e funcionalidade à Corte Penal Internacional, alvejando os objetivos consagrados no preâmbulo do Estatuto de Roma, essa relação de interdependência tem colocado em risco a própria subsistência da Corte Penal Internacional.

Nesse sentido, com especial enfoque na perspectiva da pena no contexto do direito penal internacional, Dissenha (2013, p. 194) sintetiza que: 
ao depender de uma construção horizontal para que a existência da pena internacional seja possível, a materialização da justiça penal torna-se dependente de um jogo de forças que pode desnaturar a proposta penal e, mais do que isso, pode torná-la um mero exercício de poder antidemocrático.

Assim, ao observar o cenário do direito penal internacional atual, verifica-se que a atuação da Corte Penal Internacional exclusivamente no aspecto repressivo, limitado conforme estipulado pelo Estatuto de Roma, resta insuficiente para atingir os objetivos colocados para a Corte pela comunidade internacional.

Destarte, analisaram-se os motivos elencados pelos Estados da África do Sul, Gâmbia e Burundi ao anunciarem que se retirariam do Estatuto de Roma, as limitações ao escopo de atuação da Corte, bem como os impasses por ela enfrentados para promover a persecução de Al Bashir, à luz das normas que pautam seu sistema de jurisdição e admissibilidade e de sua natureza como instituição perante a comunidade internacional.

Dessa análise, verifica-se que o esforço hercúleo despendido pela Corte Penal Internacional para manter tanto os objetivos de proteção aos direitos humanos, quanto as condições impostas por um paradigma baseado na abordagem voltada para o Estado, tal como se intentou no processo de redação do Estatuto de Roma, tornou-se insuficiente, de modo que se denota imprescindível abrir mão das premissas da abordagem voltada para o Estado.

\section{A EMERGÊNCIA DO PARADIGMA BASEADO NO HUMAN RIGHTS APPROACH}

Assim, destaca-se que a crise do paradigma baseado na abordagem voltada para o Estado, evidenciada no âmbito de atuação da Corte Penal Internacional, guarda estrita relação com a insurgência de um novo paradigma no direito internacional, embasado nos ideais de proteção aos direitos humanos.

Nesse sentido, observa-se que os tribunais internacionais cumprem um significativo papel, na medida em que

[t]êm superado a dimensão interestatal clássica, insatisfatória e perigosa (ao deixar os seres humanos à mercê dos Estados em que se encontrem), ao estenderem a via judicial para a solução pacífica de controvérsias, surgidas nos planos tanto interestatal como intraestatal. (CANÇADO TRINDADE, 2013, p. 112).

Pontua-se então a importância de que esses tribunais prezem o jus necessarium, em detrimento do jus voluntarium (CANÇADO TRINDADE, 2013, p. 39), para que seja efetiva a proteção dos direitos humanos de todos os indivíduos, independentemente da voluntariedade do Estado em que esse indivíduo se encontra. 
Esse paradigma, que volta a ótica de interpretação das normas que compõem um ordenamento jurídico para as necessidades dos seres humanos que estão no centro dos objetivos desses sistemas, em detrimento dos interesses dos Estados que os cercam, tem especial relevância no direito penal internacional, na medida em que esse ramo do direito, de maneira ampla, tem como bem jurídico tutelado os direitos humanos.

\subsection{A ABORDAGEM BASEADA NOS DIREITOS HUMANOS}

O human rights approach, ou uma abordagem baseada nos direitos humanos, desenvolve-se em uma epistemologia fundada na soberania popular. No âmbito do direito internacional, os direitos humanos foram responsáveis por ressignificar as relações internacionais (TEITEL, 2011, p. 225).

No mesmo sentido ressaltou o Tribunal Penal Internacional para a ex-Iugoslávia, no caso Promotor vs. Tadic: “[u]ma abordagem orientada pela soberania estatal tem sido gradualmente suplantada por uma abordagem orientada pelo ser humano"8 (INTERNATIONAL TRIBUNAL FOR THE PROSECUTION OF PERSONS RESPONSIBLE FOR SERIOUS VIOLATIONS OF INTERNATIONAL HUMANITARIAN LAW COMMITTED IN THE TERRITORY OF FORMER YUGOSLAVIA SINCE 1991, 1995, tradução nossa).

Esse contexto, aliado à crise do paradigma pautado pela abordagem voltada para o Estado, desde logo fomenta o diálogo entre jurisdições, o que, por sua vez, respalda o ius commune, conforme defende Piovesan (2013, p. 342) ao tratar do diálogo jurisdicional no contexto latino-americano.

O human rights-based approach, ou ainda, uma abordagem baseada nos direitos humanos, pode ser aplicado a uma grande variação de campos (FUENTES-JULIO; IBRAHIM, 2019, p. 262). Assim, em consonância com o campo em que é aplicado, o conceito de human rights approach encontra variações.

Em referência ao diálogo jurisdicional no contexto latino-americano, o human rights approach, também referido como human-centered approach, é definido como "um prisma que abarca como conceitos estruturais e fundantes a soberania popular e a segurança cidadã no âmbito interno" (PIOVESAN, 2013, p. 401). Essa abordagem, portanto, encontra sua validade no ideal de soberania popular e de tutela dos direitos humanos.

Em turno, quando aplicada para a resolução de conflitos, essa abordagem é denominada human rights-based approach, definido como um quadro conceitual cujas normas se baseiam em

8 No original: “[a] State-sovereignty oriented approach has been gradually supplanted by a human-being oriented approach.” 
direitos humanos internacionalmente reconhecidos e que se volta para promover e proteger direitos humanos (FUENTES-JULIO; IBRAHIM, 2019, p. 263).

Por sua vez, no âmbito do desenvolvimento humano, o conceito de human rights-based approach é adotado como “uma maneira (ou um 'método') de implementar direitos humanos”9 (BROBERG; SANO, 2017, p. 665, tradução nossa). Esse conceito foi posteriormente desenvolvido e ainda compreende que human rights-based approach "procura analisar desigualdades que estão no cerne dos problemas de desenvolvimento e corrigir práticas discriminatórias e distribuições injustas de poder que impedem o progresso do desenvolvimento"10 (UNITED NATIONS, 2006, p. 15, tradução nossa).

Para o propósito do presente trabalho o human rights approach, daqui em diante referido como abordagem de direitos humanos, é um conjunto de normas e um meio de interpretação que visa concretizar direitos humanos, por meio da difusão desses direitos e do empoderamento de seus titulares, e que encontra sua validade nos próprios direitos humanos. Trata-se, portanto, de um conceito que se relaciona com os direitos humanos em uma tríplice vertente.

Não obstante a abordagem de direitos humanos encontre variações em seu conceito, em todas as suas aplicações, essa abordagem dá ênfase à implementação de direitos humanos por meio de princípios de não discriminação e participação (BROBERG; SANO, 2017, p. 665). Fuentes-Julio e Ibrahim (2019) ainda sintetizam que em todas as aplicações essa abordagem possui quatro características constantes.

A primeira característica consiste no objetivo de efetivar os direitos humanos, como postulados pela Declaração Universal de Direitos Humanos ou por outros tratados. Em seguida, a segunda característica está relacionada com a dualidade entre a primazia pelas garantias conferidas aos sujeitos de direito e as obrigações dos responsáveis por assegurar essas garantias. "Uma abordagem baseada nos direitos humanos objetiva desenvolver as capacidades dos sujeitos de direito de clamar seus direitos e o dos responsáveis em cumprir suas obrigações de respeitar, proteger e concretizar esses direitos”11 (FUENTES-JULIO; IBRAHIM, 2019, p. 263, tradução nossa).

A terceira característica, por sua vez, é que uma abordagem de direitos humanos se pauta na observância de princípios de direitos humanos. Por fim, a quarta característica é que uma abordagem de direitos humanos destaca assimetria de poder e desigualdade, na medida em que os direitos

9 No original: “[...] a way (or a 'method') of implementing human rights”.

10 No original: "[...] seeks to analyse inequalities which lie at the heart of development problems and redress discriminatory practices and unjust distributions of power that impede development progress.”

11 No original: "A human rights-based approach aims to develop the capacities of rights holders to claim their rights and of duty bearers to meet their obligations to respect, protect, and fulfill these rights.” 
humanos têm como finalidade a proteção de grupos vulneráveis ao abuso dos Estados e de outros agentes potencialmente exploradores (FUENTES-JULIO; IBRAHIM, 2019, p. 263).

Nesse sentido, cabe tomar como exemplo a mudança de paradigma, operada pelas Nações Unidas no âmbito das missões de paz, para uma abordagem centrada nas pessoas. Atestando que justiça, o Estado de Direito e os direitos humanos revigoram mutuamente seu trabalho, a ONU reconheceu que com muita frequência abordou “justiça e Estado de Direito de um lado e direitos humanos de outro, como áreas separadas de atuação”12 (UNITED NATIONS, 2015, p. 40, tradução nossa).

Desse modo, o desenvolvimento do Estado de Direito nem sempre observou os direitos humanos e, por vezes, falhas ou atrasos no desenvolvimento de um lado da abordagem impactaram negativamente o outro. Assim, a organização concluiu que:

Operações de paz da ONU devem trabalhar para assegurar que o Estado de Direito opere de maneira que proteja os direitos humanos. Isso inclui enfrentar a impunidade, por meio de suporte a mecanismos apropriados de justiça de transição, em que violações passadas não foram resolvidas e serão um obstáculo para a paz duradoura ${ }^{[13]}$ (UNITED NATIONS, 2015, p. 40, tradução nossa).

Ante esse panorama, as Nações Unidas afirmaram seu compromisso em se tornar uma organização mais orientada pelo campo de atuação e centrada nas pessoas no que se refere às operações de paz. "Isso requer abordagens modernizadas e estruturas que possibilitem flexibilidade e melhores respostas do sistema ONU na área. Requer maior engajamento com as comunidades para ajudar a melhorar a execução de mandatos”14 (UNITED NATIONS, 2015, p. 40, tradução nossa).

Para atingir esse objetivo o Fundo Fiduciário de Segurança Humana das Nações Unidas resolveu, em 2016, que a abordagem para a segurança humana deve ser centrada nas pessoas e “considerar o amplo alcance das condições que ameaçam a sobrevivência, subsistência e dignidade das pessoas e de suas comunidades, particularmente aquelas que são mais vulneráveis”15 (UNITED NATIONS, 2016, p. 7, tradução nossa).

Isso possibilita atribuir igual importância para os direitos civis, políticos, econômicos, sociais e culturais dos indivíduos e das comunidades, bem como revelar a real situação desses sujeitos

12 No original: “[...] justice and the rule of law, on the one hand, and human rights on the other, as separate areas of operation.”

13 No original: "UN peace operations should work to ensure that the rule of law operates in a manner that protects human rights. This includes addressing impunity, through supporting appropriate mechanisms of transitional justice where past violations have not been resolved and will be an obstacle to lasting peace."

14 No original: "This requires modernized approaches and structures to enable flexible and better UN System responses in the field. It requires greater engagement with communities to help improve mandate implementation.”

15 No original: "[...] the broad range of conditions that threaten the survival, livelihood and dignity of people and their communities, particularly those who are most vulnerable.” 
de direito, permitindo melhor compreensão sobre os diferentes tipos de ameaças e vulnerabilidade enfrentadas por esses sujeitos (UNITED NATIONS, 2016, p. 18).

Essa abordagem é inclusiva e participativa, e garante participação da comunidade para a definição de suas necessidades e capacidades de modo a se administrar expectativas e reforçar harmonia social (UNITED NATIONS, 2016, p. 17). Ademais, afirma-se que a abordagem

[...] pode interligar a sociedade civil e organizações baseadas na comunidade, melhorar a administração estratégica de recursos voluntários e fortalecer a delegação de responsabilidades entre grupos da sociedade civil, governos e a comunidade internacional ${ }^{[16]}$ (UNITED NATIONS, 2016, p. 15, tradução nossa).

Assim, denota-se que uma abordagem de direitos humanos, como um conjunto de normas e um meio de interpretação, é apta para concretizar direitos humanos e empoderar seus titulares, por meio da própria difusão desses direitos, de modo a contribuir de forma significativa para o desenvolvimento comunitário.

\subsection{A EMERGÊNCIA DA ABORDAGEM DE DIREITOS HUMANOS NO ESCOPO DE ATUAÇÃO DA CORTE PENAL INTERNACIONAL}

Sob a mesma ótica, a Corte Penal Internacional, com base nos ideais de Direitos Humanos e Soberania Popular, conferindo primazia à abordagem de direitos humanos em detrimento dos princípios pautados na abordagem voltada para o Estado, pode ampliar sua atuação visando o desenvolvimento do ius commune internacional, ao atuar em conjunto com as jurisdições nacionais para a persecução penal de casos não admissíveis à jurisdição da Corte, bem como para implantar iniciativas voltadas para a prevenção criminal, com a finalidade de garantir maior aproximação aos objetivos postulados pelo Estatuto de Roma.

Denota-se, inclusive, que os tribunais internacionais já desempenham um papel histórico ao preconizar proteção aos mais vulneráveis, àqueles que necessitam da comunidade internacional, cuja denominação refere-se à humanização do direito internacional contemporâneo (CANÇADO TRINDADE, 2013, p. 48).

Nesse diapasão, cumpre dar o devido destaque aos ideais encadernados no preâmbulo do Estatuto de Roma pela comunidade internacional, nos termos do Decreto ${ }^{\circ}$ 4.388/2002:

16 No original: “[...] can help promote networking among civil society and community-based organisations, improve the strategic management of volunteer resources, and strengthen the delegation of responsibilities among civil society groups, Governments and the international community.” 
[c]onscientes de que todos os povos estão unidos por laços comuns e de que suas culturas foram construídas sobre uma herança que partilham, e preocupados com o fato deste delicado mosaico poder vir a quebrar-se a qualquer instante,

Tendo presente que, no decurso deste século, milhões de crianças, homens e mulheres têm sido vítimas de atrocidades inimagináveis que chocam profundamente a consciência da humanidade,

Reconhecendo que crimes de uma tal gravidade constituem uma ameaça à paz, à segurança e ao bem-estar da humanidade (BRASIL, 2002).

Assim, tendo em vista as recentes evidências de que o paradigma baseado na abordagem voltada para o Estado não é sustentável perante os objetivos, da Corte Penal Internacional, de proteção aos direitos humanos, denota-se imprescindível a releitura de princípios como o da complementaridade, soberania e pacta sunt servanda, o que permite uma maior compatibilização entre as normas que limitam o escopo de atuação da Corte Penal Internacional e os objetivos postulados pelo Estatuto de Roma, em consonância ao paradigma pautado na abordagem de direitos humanos.

\subsubsection{A relação entre a releitura dos princípios pautados na abordagem voltada para o Estado e os direitos dos réus perante a Corte Penal Internacional}

No entanto, é necessário reconhecer que os princípios pautados na abordagem voltada para o Estado, para além da influência no escopo de jurisdição da Corte Penal Internacional, conforme anteriormente mencionado, guardam estrita relação com princípios do direito criminal incorporados no Estatuto de Roma, que visam à proteção dos direitos do acusado.

Notadamente, uma vez que os princípios da soberania, complementaridade e pacta sunt servanda limitam a jurisdição da Corte Penal Internacional apenas aos Estados que ratificaram o Estatuto de Roma, é possível arguir que flexibilizar a aplicação desses princípios fere o princípio nullum crimen sine lege, previsto no artigo 22 do Estatuto de Roma (INTERNATIONAL CRIMINAL COURT, 1998). Isso porque tal flexibilização implicaria a aplicação das normas penais do Estatuto a nacionais de um Estado que não faz parte do Tratado, de modo a acessar responsabilidade criminal por condutas que, ao momento de sua perpetração, não constituíam crime sob o ordenamento jurídico aplicável àquele sujeito.

Todavia, ressalva-se que, ao se ressignificarem os princípios anteriormente mencionados, pautados na abordagem voltada para o Estado, não se comprometem incontinenti os princípios de direito penal incorporados pelo Estatuto de Roma, em especial o princípio nullum crimen sine lege, tendo em vista que a Corte Penal Internacional não está limitada à atuação jurídica penal repressiva. 
Verifica-se que a Corte Penal Internacional já possui iniciativas mediante as quais estabelece um diálogo com as comunidades envolvidas em situações sob investigação. A título de exemplo, menciona-se evento realizado pela Corte Penal Internacional na Universidade Católica do Congo a fim de estabelecer diálogo com estudantes de direito e de comunicação a respeito do Estatuto de Roma e do caráter complementário da Corte (INTERNATIONAL CRIMINAL COURT, 2019a).

Da mesma maneira, também na República Democrática do Congo, a Corte promoveu diversos encontros com as comunidades afetadas por crimes julgados pela Corte, entre oito de julho ${ }^{17}$ e 17 de julho de 2019, visando estabelecer um diálogo com a comunidade para identificar as especificidades do acesso à justiça para aqueles afetados pelo caso Promotor v. Bosco Ntaganda (COUR PÉNALE INTERNATIONALE, 2019; INTERNATIONAL CRIMINAL COURT, 2019b).

Por fim, destaca-se o workshop promovido pela Corte para a Associação de Mulheres Jornalistas na República Centro-Africana, para difundir conhecimento sobre a atuação da Corte e iniciar projetos para fornecer melhor acesso à justiça, por meios de comunicação do país, em especial para as mulheres e meninas das comunidades da República Centro-Africana afetadas por crimes julgados pela Corte Penal Internacional (INTERNATIONAL CRIMINAL COURT, 2019c).

Desse modo, conclui-se que um paradigma pautado na abordagem de direitos humanos pode conciliar a proteção dos direitos do acusado, considerados também direitos humanos de imperativa observação, ao manter os limites de jurisdição da Corte no que se refere à persecução criminal, com uma atuação mais efetiva da Corte Penal Internacional, na forma do fomento à reestruturação das comunidades, orientado por uma abordagem centrada nas pessoas, como a Corte já faz nos casos em que os requisitos de jurisdição estão presentes.

\subsubsection{A possibilidade de atuação da Corte Penal Internacional fora do escopo da persecução penal}

Isso posto, para que a Corte Penal Internacional fomente a reestruturação das comunidades afetadas pelos crimes previstos no Estatuto de Roma, orientando-se por uma abordagem centrada nas

17 Data do julgamento do caso Promotor x Bosco Ntaganda, na República Democrática do Congo (Caso ICC-01/0402/06). 
pessoas, do mesmo modo que nas situações em que os requisitos de jurisdição estão presentes, é preciso que a organização amplie seu escopo de atuação.

Nesse sentido, a Corte contribuiria para que o direito penal internacional encontre meios de conciliar tanto a justiça repressiva quanto "uma perspectiva propositiva de reconhecimento dos problemas e construção de soluções” (DISSENHA, 2013, p. 342).

No que se refere à ampliação do escopo de atuação da Corte Penal Internacional para além dos objetivos de persecução criminal, faz-se necessário aliar o aspecto repressivo do direito penal internacional com uma perspectiva prospectiva de efetiva prevenção.

Dessa forma, unindo-se as vertentes prospectiva e repressiva limitada de uma política criminal para a justiça penal internacional, é possível transformá-la em uma construtora da cidadania universal que, dentro de limites adequados, serve à garantia da coexistência. (DISSENHA, 2013, p. 290).

Outrossim, destaca-se que para a construção de uma cidadania universal, conforme propõe Dissenha (2013), ou ainda do ius commune internacional, a atuação da Corte pode tanto unir política criminal repressiva e prospectiva de prevenção, quanto aproximar-se das jurisdições nacionais para, juntamente com as populações que se veem envoltas em situações de crimes internacionais, promover o restabelecimento de instituições jurídicas e promover a persecução penal em um nível nacional, assim aproximando-se dos objetivos propostos no preâmbulo do Estatuto de Roma.

A atuação da Corte nesse sentido, com o fito de fomentar o ius commune, também possui respaldo, na medida em que as jurisdições nacionais amparam a evolução e o aumento de atuação do direito internacional (CANÇADO TRINDADE, 2013, p. 86).

\footnotetext{
O direito internacional atribui funções internacionais também aos tribunais nacionais. Estes últimos têm um papel a exercer também na busca do primado do rule of law internacional. A expansão da jurisdição internacional se dá pari passu com a expansão tanto da personalidade como da responsabilidade internacionais - apontando todas à atual construção de um novo jus gentium de nossos tempos. (CANÇADO TRINDADE, 2013, p. 86).
}

Nesse aspecto, é imperioso que a construção do ius commune internacional se desenvolva sob o prisma de princípios que permitam flexibilidade e permeabilidade à ação de entes internacionais como a Corte Penal Internacional, a exemplo da abordagem de direitos humanos.

Diante da imprescindibilidade de uma releitura dos princípios voltados para a proteção do Estado e da sua aplicabilidade na jurisdição da Corte Penal Internacional, tem-se como primordial uma interpretação fundada nos Direitos Humanos:

[f]az-se fundamental transitar da pirâmide jurídica hermética fundada no State approach para a permeabilidade do trapézio jurídico fundado no Human Rights approach. A emergência deste novo paradigma demanda o desafio de projetar uma nova visão do Direito, o que requer 
profundas transformações no ensino jurídico, na metodologia e na pesquisa jurídica. (PIOVESAN, 2013, p. 406).

Veja-se que não há conflito ou concorrência entre as jurisdições nacionais e internacionais, mas sim uma relação de frequente interação, verdadeiramente complementar para garantir proteção aos direitos humanos e responsabilização daqueles que os violam (CANÇADO TRINDADE, 2013, p. 86). Nesse sentido:

É de se esperar que, nestes novos tempos, se consolide enfim a aplicação do princípio da jurisdição universal, em meio à expansão da função judicial internacional, na busca da realização do antigo ideal da justiça em nível internacional. Em uma dimensão mais ampla, todos os tribunais internacionais têm contribuído, cada um a seu modo, à revitalização dos princípios gerais do direito (inclusive os do direito internacional). (CANÇADO TRINDADE, 2013, p. 79).

Assim, sugere-se que, nas situações em que a Corte Penal Internacional não possua jurisdição para a persecução criminal, mas que ainda haja interesse da população local para a resolução de conflitos que englobem crimes previstos no artigo $5^{\circ}$ do Estatuto de Roma (INTERNATIONAL CRIMINAL COURT, 1998), a Corte amplie seu escopo de atuação.

Por intermédio da releitura dos princípios pautados na abordagem voltada para o Estado, dando lugar a uma abordagem de direitos humanos, pautada em um ideal de soberania popular, é possível que a Corte trabalhe em conjunto com as comunidades afetadas por esses crimes, levando para esses locais iniciativas semelhantes às já adotadas em situações que foram efetivamente processadas na Corte Penal Internacional.

\section{CONSIDERAÇÕES FINAIS}

O presente trabalho se determinou a identificar a influência de princípios de direito internacional público presentes na delimitação do escopo de jurisdição da Corte Penal Internacional, a eficácia da atuação da Corte e examinar o prelúdio e a viabilidade de uma mudança paradigmática, baseada em uma abordagem de direitos humanos.

Assim, mediante o estudo de tratados e de entendimentos jurisprudenciais de cortes internacionais, o trabalho analisou o embate que há na comunidade internacional quanto à conciliação da proteção dos direitos humanos e a conservação dos ideais de proteção estatal, pontuando a relativização do último em decorrência da necessidade de se proteger direitos humanos.

Assim, a pesquisa constatou que o direito internacional público, ante o embate entre os princípios pautados na abordagem voltada para o Estado e os princípios de proteção aos direitos humanos, tem desenvolvido uma tendência de dar primazia aos ideais relacionados à abordagem de 
direitos humanos. Todavia, notou-se também que a relativização dos princípios de proteção estatal tem se mostrado insuficiente para a resolução de conflitos com normas que protegem os direitos humanos, o que evidencia a crise que o paradigma baseado em uma abordagem voltada para o Estado enfrenta perante a comunidade internacional.

O trabalho ainda se voltou a identificar sintomas dessa crise de paradigma na atuação da Corte Penal Internacional, com enfoque no estudo dos motivos elencados pelos Estados da África do Sul, Gâmbia e Burundi ao anunciarem que deixariam o Estatuto de Roma e dos impasses enfrentados pela instituição para fazer cumprir sua decisão de emitir um mandado de prisão em face do então Presidente do Sudão, Omar Al Bashir, possibilitando sua persecução perante a Corte Penal Internacional.

Mediante o aludido estudo, verificou-se uma ligação entre as dificuldades analisadas e as normas compreendidas na estrutura jurídica da Corte que encontram embasamento na abordagem voltada para o Estado. Pontuou-se, portanto, que, não obstante a abordagem voltada para o Estado se determine a garantir funcionalidade à Corte Penal Internacional, tal relação tornou-se um empecilho para a subsistência da Corte como instituição.

Destarte, a pesquisa voltou-se para a insurgência de um novo paradigma no direito internacional, embasado nos ideais de proteção aos direitos humanos. Dessa maneira, a abordagem de direitos humanos foi definida aliando-se pesquisa doutrinária à análise da reestruturação em segmentos da Organização das Nações Unidas pautados nessa abordagem. Assim, concluiu-se que a abordagem de direitos humanos é conjunto de normas e meio de interpretação que visa concretizar direitos humanos, por meio da difusão desses direitos e do empoderamento de seus titulares, e que encontra sua validade nos próprios direitos humanos.

Buscou-se então identificar como a abordagem de direitos humanos pode se concretizar mediante ações que a Corte Penal Internacional realiza nas comunidades afetadas por crimes processados na Corte, reproduzidas em comunidades afetadas por crimes internacionais que não estão sob sua jurisdição. Avaliou-se, por fim, a compatibilidade dessa abordagem com a proposta da Corte Penal Internacional, em especial no que se refere aos direitos do acusado.

Nesse aspecto, propõe-se que a Corte Penal Internacional amplie seu escopo de atuação, valendo-se de uma reinterpretação dos princípios pautados na abordagem voltada para o Estado, que dê lugar a uma abordagem de direitos humanos, de modo a se alcançar situações em que, embora não haja jurisdição para a persecução criminal, ainda se verifique interesse da população local para a resolução de conflitos que englobem crimes previstos no artigo $5^{\circ}$ do Estatuto de Roma. 


\section{REFERÊNCIAS}

BARNES, Gwen P. The International Criminal Court's Ineffective Enforcement Mechanisms: The Indictment of President Omar Al Bashir. Fordham International Law Journal, [s. l.], v. 34, n. 6, p. 1.585-1.619, 13 jun. 2011.

BARREIROS, Lucas Emiliano. Contemporary International Law and the Question of Sovereignty: An Attempt at Reconciliation. 2008. 77 f. Dissertação (Mestrado em Direito) Harvard Law School, Cambridge, MA, 2008.

BOBBIO, Norberto. Era dos Direitos. Tradução Carlos Nelson Coutinho. Rio de Janeiro: Elsevier, 2004.

BRASIL. Decreto $n^{\circ}$ 4.388, de 25 de setembro de 2002. Promulga o Estatuto de Roma do Tribunal Penal Internacional. Diário Oficial [da] República Federativa do Brasil, Brasília, DF, 26 set. 2002.

BROBERG, Morten; SANO, Hans-Otto. Strengths and weaknesses in a human rights-based approach to international development - an analysis of a rights-based approach to development assistance based on practical experiences. The International Journal of Human Rights, [s. l.], v. 22, n. 5, p. 664-680, dez. 2017.

CANÇADO TRINDADE, Antônio Augusto. Tribunais internacionais contemporâneos. Brasília: Funag, 2013.

COUR PÉNALE INTERNATIONALE. Situation in Dafur, Sudan, in the case of The Prosecutor v. Omar Hassan Ahmad al Bashir (“Omar Albashir”). Julgamento de 4 de março de 2009. Disponível em: https://bit.ly/3s9inDI. Acesso em: 6 nov. 2019.

COUR PÉNALE INTERNATIONALE. Situation in Darfur, Sudan. The Prosecutor v. Omar Hassan Ahmad al Bashir. Second Decision on the Prosecution's Application for a Warrant of Arrest. Julgamento de 12 de julho de 2010. Disponível em: https://bit.ly/3wIHscc. Acesso em: 6 nov. 2019.

COUR PÉNALE INTERNATIONALE. Situation in the Democratic Republic of the Congo, in the case of The Prosecutor v. Bosco Ntaganda. Julgamento de 8 de julho de 2019. Disponível em: https://bit.ly/3rZrtTu. Acesso em: 19 fev. 2020.

DISSENHA, Rui Carlo. Por uma Política Criminal Universal: uma crítica aos Tribunais Penais Internacionais. 2013. 377 f. Tese (Doutorado em Direitos Humanos) - Universidade de São Paulo, São Paulo, 2013.

DOMINGOS, Rafael. The Crisis of International Law. Vanderbilt Journal of Transnational Law, Nashville, TN, v. 42, n. 5, p. 1.544-1.593, jul. 2012.

DYANI-MHANGO, Ntombizozuko. South Africa's (unconstitutional) withdrawal from the Rome Statute: A note on Democratic Alliance v. Minister of International Relations and Cooperation. South African Journal on Human Rights, Johannesburg, v. 34, n. 2, p. 268-289, 21 set. 2018. 
FUENTES-JULIO, Claudia; IBRAHIM, Raslan. A Human Rights Approach to Conflict Resolution. Ethics \& International Affairs, [s. l.], v. 33, n. 3, p. 261-273, set. 2019.

GAMBIA Announces Withdrawal from International Criminal Court. Reuters Staff. Reporting by Joe Bavier; Editing by Sandra Maler and Peter Cooney. London: Thomson Reuters, 25 out. 2016. Disponível em: https://reut.rs/2QffpjC. Acesso em: 5 nov. 2019.

GREENAWALT, Alexander K. A. Introductory Note to the International Criminal Court: Decisions Pursuant to Article 87(7) of the Rome Statute on the Failure by the Republic of Malawi and the Republic of Chad to Comply with the Cooperation Requests Issued by the Court with Respect to the Arrest and Surrender of Omar Hassan Ahmad Al Bashir \& African Union Response. International Legal Materials, [s. l.], v. 51, n. 2, p. 393-417, 2012.

GÜMPLOVÁ, Petra. On Sovereignty and Post-sovereignty. Philosophica Critica, Nitra, v. 1, n. 2, p. 3-18, 2015.

INTERNATIONAL CRIMINAL COURT (ICC). ICC Outreach in DRC has been... Haia, 20 de julho de 2019b. Facebook: InternationalCriminalCourt. Disponível em: https://bit.ly/3dO0bKF. Acesso em: 19 fev. 2020.

INTERNATIONAL CRIMINAL COURT (ICC). ICC outreach in DRC this week... Haia, 27 de outubro de 2019a. Facebook: InternationalCriminalCourt. Disponível em: https://bit.ly/2QcwKKl. Acesso em: 19 fev. 2020.

INTERNATIONAL CRIMINAL COURT (ICC). The ICC hosted a workshop for over... Haia, 21 de julho de 2019c. Facebook: InternationalCriminalCourt. Disponível em: https://bit.ly/2RcJTTZ. Acesso em: 19 fev. 2020.

INTERNATIONAL CRIMINAL COURT. Rome Statute of the International Criminal Court. The Hague: International Criminal Court, 1998. Disponível em: https://bit.ly/3t5Acol. Acesso em: 19 fev. 2020.

INTERNATIONAL TRIBUNAL FOR THE PROSECUTION OF PERSONS RESPONSIBLE FOR SERIOUS VIOLATIONS OF INTERNATIONAL HUMANITARIAN LAW COMMITTED IN THE TERRITORY OF FORMER YUGOSLAVIA SINCE 1991 (“International Tribunal”). Prosecutor v. DUSKO TADIC a/k/a "DULE”. Case No. IT-94-1-T. Appeals Chamber. Decision on the Defence Motion for Interlocutory Appeal on Jurisdiction. Decisão de 2 de outubro de 1995. The Hague: International Tribunal, 1995. Disponível em: https://bit.ly/3s285oR. Acesso em: 24 ago. 2019.

PIOVESAN, Flávia. Estudos Avançados de Direitos Humanos. Direitos humanos e diálogo jurisdicional no contexto latino-americano. Rio de Janeiro: Elsevier, 2013.

SSENYONJO, Manisuli. State Withdrawal Notifications from the Rome Statute of the International Criminal Court: South Africa, Burundi and the Gambia. Criminal Law Forum, [s. l.], v. 29, n. 1, p. 63-119, 13 jun. 2017.

TEITEL, Ruti. Humanity’s Law. Oxford: Oxford University Press, 2011. 
UNITED NATIONS. High Commissioner for Human Rights. Frequently Asked Questions on a Human Rights-Based Approach to Development Cooperation. New York: United Nations, 2006. Disponível em: https://bit.ly/3d4VfSI. Acesso em: 27 maio 2020.

UNITED NATIONS. Human Security Handbook. An integrated approach for the realization of the Sustainable Development Goals and the priority areas of the international community and the United Nations system. New York: United Nations, janeiro 2016. Disponível em: https://bit.ly/3wIIBk0. Acesso em: 19 fev. 2020.

UNITED NATIONS. Uniting our strengths for peace - politics, partnership and people. Report of the High-Level Independent Panel on United Nations Peace Operations. 16 junho 2015. Disponível em: https://bit.ly/3uzv7VV. Acesso em: 19 fev. 2020. 